\title{
Evaluation of pharmacoinvasive strategy versus percutaneous coronary intervention in patients with acute myocardial infarction with ST-segment elevation at the National Institute of Cardiology (PHASE-MX)
}

\section{Evaluación de la estrategia farmacoinvasiva versus angioplastia coronaria transluminal percutánea primaria en pacientes con infarto agudo de miocardio con elevación del segmento ST en el Instituto Nacional de Cardiología (PHASE-MX)}

Luis A. Baeza-Herrera1', Diego Araiza-Garaygordobil'*, Rodrigo Gopar-Nieto', Grecia I. Raymundo-Martínez', Arnoldo Loáisiga-Sáenz' ${ }^{1}$, Abraham Villalobos-Flores ${ }^{1}$, Manuel Martínez-Ramos ${ }^{1}$, Laura V. Torres-Araujo ${ }^{1}$, Ricardo Pohls-Vázquez'1, Abraham Luna-Herbert', Arturo Alonso-Vázquez'1, Itzel V. Delgado-Cruz', Alejandro Cabello-López², Pablo Martínez-Amezcua³, and María A. Arias-Mendoza ${ }^{1}$

${ }^{1}$ Department of Emergency, Coronary Care Unit, Instituto Nacional de Cardiología Ignacio Chávez; ${ }^{2}$ Occupational Health Research Unit, Centro Médico Nacional Siglo XXI, Instituto Mexicano del Seguro Social. Mexico City, Mexico; ${ }^{3}$ Department of Epidemiology, Johns Hopkins Bloomberg School of Public Health, Baltimore, Maryland, USA

\begin{abstract}
Objective: The objective of PHASE-MX registry is to validate the efficacy and safety of the pharmacoinvasive strategy in comparison with percutaneous coronary intervention $(\mathrm{PCl})$ in patients with acute myocardial infarction with ST segment elevation (STEMI) in a metropolitan region of Mexico. The primary outcome will consist of the composite of cardiovascular death, re-infarction, stroke and cardiogenic shock. Methods: The PHASE-MX registry will include a prospective cohort of patients with STEMI who received reperfusion treatment (mechanical of pharmacological) in the first $12 \mathrm{~h}$ after the onset of symptoms. The registry is designed to compare the efficacy and safety of primary $\mathrm{PCl}$ and pharmacoinvasive strategy. The simple size was calculated in 344 patients divided into two groups, with an estimated loss rate of $10 \%$. Patients included in the PHASE-MX cohort will be followed for up to one year. Conclusion: In Mexico, only 5 out of 10 patients with STEMI have access to reperfusion therapy. Pharmacoinvasive strategy is takes advantage of the accessibility of fibrinolysis and the effectiveness of $\mathrm{PCl}$. The present research protocol aims to provide information that serves as a link between information derived from controlled clinical trials and records derived from real world experience.
\end{abstract}

Key words: Acute myocardial infarction. Pharmacoinvasive. Reperfusion. Mexico.

Correspondence:

*Diego Araiza-Garaygordobil

E-mail: dargaray@gmail.com
Date of reception: 10-04-2019

Date of acceptance: 06-12-2019

DOI: 10.24875/ACME.M20000107
Available online: 04-09-2020 Arch Cardiol Mex (Eng). 2020;90(2):137-141 www.archivoscardiologia.com license (http://creativecommons.org/licenses/by-nc-nd/4.0/). 


\section{Resumen}

Objetivo: El objetivo del registro PHASE-MX es validar la eficacia y seguridad de la estrategia farmacoinvasiva en comparación con la angioplastia coronaria transluminal percutánea primaria (ACTPp) en pacientes con infarto agudo de miocardio con elevación del segmento ST (IAMCEST) en una región metropolitana de México. El desenlace primario es el compuesto de muerte cardiovascular, reinfarto, accidente vascular cerebral y choque cardiogénico. Métodos: El registro PHASE-MX es una cohorte prospectiva de pacientes con IAMCEST que recibieron tratamiento de reperfusión (mecánico o farmacológico) en las primeras 12 horas desde el inicio de los síntomas, atendidos en el Instituto Nacional de Cardiología Ignacio Chávez. El análisis estadístico se basa en la no inferioridad de la estrategia farmacoinvasiva en comparación con la ACTPp. Se calcula un tamaño de muestra de 344 pacientes divididos en dos grupos (angioplastia primaria y estrategia farmacoinvasiva), considerada una tasa de pérdidas de 10\%. Los pacientes incluidos en la cohorte PHASE-MX se seguirán durante un año. Discusión: En México, sólo 5 de cada 10 pacientes con IAMCEST tienen acceso al tratamiento de reperfusión. La estrategia farmacoinvasiva aprovecha la accesibilidad de la fibrinólisis y la efectividad de la ACTPp, por lo que podría resultar el método de elección en el tratamiento del IAMCEST en la mayoría de los casos. El presente protocolo de investigación pretende aportar información que sirva como enlace entre la información derivada de los estudios clínicos controlados y los registros derivados de la experiencia del mundo real.

Palabras clave: Infarto agudo de miocardio. Farmacoinvasivo. Reperfusión. México.

\section{Introduction}

Mexico is the country with the highest mortality rate of ST-segment elevation myocardial infarction (STEMI) among the Organization for Economic Cooperation and Development (OECD) member countries, with an estimate of 26.6/100 discharges, in comparison with OECD average of 8 deaths $/ 100$ discharges 1 .

Reperfusion treatment in STEMI has been shown to decrease long-term morbidity and mortality ${ }^{2,3}$. The European Society of Cardiology clinical practice guidelines recommend the use of fibrinolysis or primary percutaneous coronary intervention $(\mathrm{PCl})$ with a Class I recommendation and Grade A evidence, within the first $12 \mathrm{~h}$ of symptom onset ${ }^{4}$. Although pPTCA is superior to fibrinolysis when prospectively compared in randomized controlled trials ${ }^{3}$, real-life registries suggest that fibrinolysis is an efficacious treatment when timely administered and that it prevents delays related to $\mathrm{PCl}^{5,6}$.

The pharmacoinvasive strategy consists of immediate fibrinolysis and subsequent systematic coronary angiography, preferably within the first 3-24 $\mathrm{h}$ after fibrinolysis ${ }^{7}$. The advantage of this strategy allows easy access to fibrinolytic ${ }^{8}$ combined with percutaneous transluminal coronary angioplasty efficacy to prevent reinfarction and recurrent ischemia ${ }^{3}$. The pharmacoinvasive strategy has been shown not to be inferior in prospective clinical studies ${ }^{7,9}$ and real-life registries ${ }^{10}$, and multiple countries have published their experience with regard to pharmacoinvasive systems ${ }^{11}$.

The pharmacoinvasive strategy could be a feasible approach in countries and regions where access to $\mathrm{PCl}$ is limited due to geographic, cultural, or social reasons, such as Mexico. However, the pharmacoinvasive strategy has not been prospectively validated in Mexican patients with acute STEMI.

The purpose of the PHASE-MX study is to validate the efficacy and safety of the pharmacoinvasive strategy in comparison with primary angioplasty in patients with acute STEMI in a metropolitan region of Mexico.

\section{Methodology}

PHASE-MX is a prospective cohort study of patients with ST-segment elevation acute myocardial infarction treated with fibrinolysis or primary angioplasty and finally attended in a tertiary care center in Mexico City. The project is an initiative of the Emergency and Coronary Care Unit of the Ignacio Chávez National Institute of Cardiology and consists of a prospective record of all STEMI cases that received reperfusion treatment within the first $12 \mathrm{~h}$. Follow-up will be extended for up to 12 months after hospital discharge.

\section{Study population}

Patients older than 18 years with a STEMI diagnosis, attended in any of the hospitals belonging to the metropolitan area of Mexico City, in the process of reperfusion treatment (pharmacological or mechanical) within the first 12 hours of symptom onset and referred to the Ignacio Chávez National Institute of Cardiology. The area of care and reference of the Mexico City metropolitan area comprise a calculated area of $7954 \mathrm{~km}^{2}$, with a population of 20.4 million inhabitants (Fig. 1 and Table 1) ${ }^{12}$. It will not include patients whose diagnosis at hospital discharge is other than acute STEMI. 
Table 1. Hospitals by state of the metropolitan area of Mexico city that referred patients with STEMI to INCICh

\begin{tabular}{|l|c|c|}
\hline Localization of hospitals that refer to INCICh & $\begin{array}{l}\text { Average distance to INCICh (km) } \\
\text { (shortest-longest) }\end{array}$ & $\begin{array}{l}\text { Average transportation time } \\
\text { (minutes)* (shortest-Iongest) }\end{array}$ \\
\hline Mexico city (15) & $21.6(12.5-31.8)$ & $46.9(18-100)$ \\
\hline National Health Institutes** (5) & $1.9(0.5-6.6)$ & $6(3-11)$ \\
\hline State of Mexico (14) & $88.8(29.6-190)$ & $91.8(30-150)$ \\
\hline Total (34) & 37.4 & 48.2 \\
\hline
\end{tabular}

INCICh (Instituto Nacional de Cardiología Ignacio Chávez): Ignacio Chávez National Institute of Cardiology.

*Time calculated using the Google Maps app at 12:00-14:00 h, Mexico City time zone.

**Includes the National Institute of Medical Sciences and Nutrition Salvador Zubirán, General Hospital Dr. Manuel Gea González, National Institute of Respiratory Diseases Ismael Cossío Villegas, National Institute of Cancer, National Institute of Neurology and Neurosurgery Dr. Manuel Velasco.

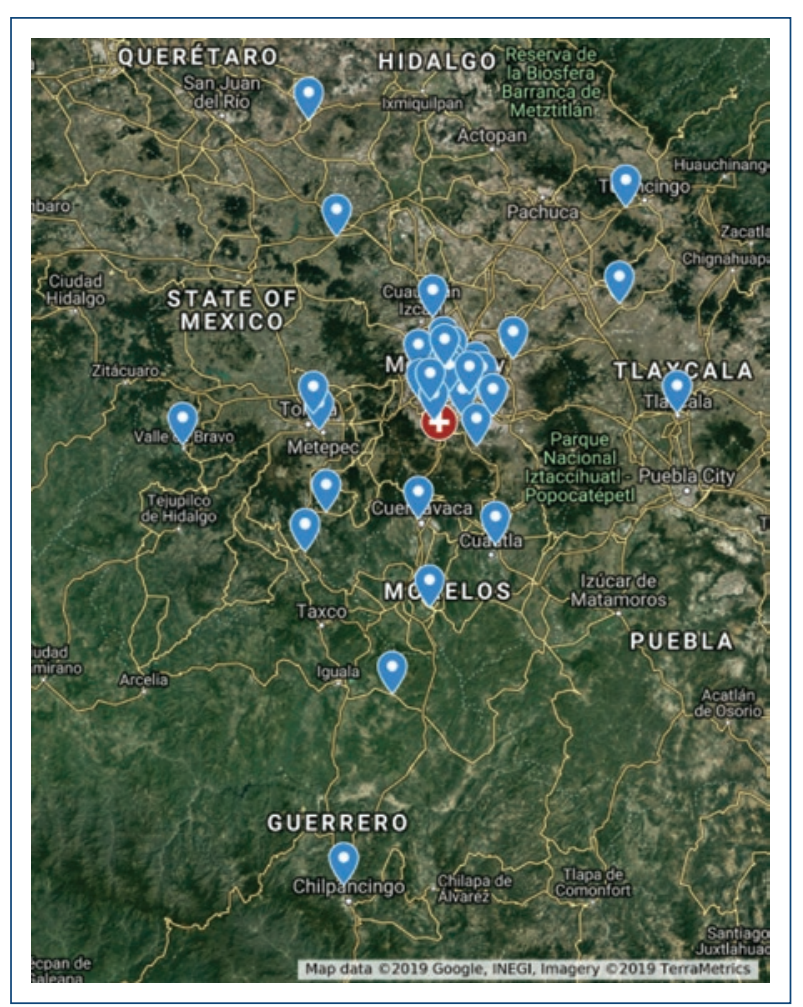

Figure 1. Satellite map showing the area served by the Ignacio Chávez National Institute of Cardiology (INCICh - Instituto Nacional de Cardiología Ignacio Chávez). Blue indicators point at the localization of hospitals where patients with STEMI received reperfusion treatment with pharmacological fibrinolysis and then were referred to the INCICh (marked on the map with a white cross on red background), for a period of approximately 1 year. The Valley of Mexico metropolitan area and the area served by INCICh have an extension of approximately 8000 and $36,000 \mathrm{~km}^{2}$, respectively.

\section{Follow-up}

From the moment of inclusion, clinical follow-up will be carried out until hospital discharge. Then, upon completing 12 months of follow-up (accounted for since hospital discharge), vital state will be analyzed by means of telephone contact.

\section{Objectives}

The general purpose of the PHASE-MX registry will be to assess the efficacy of the pharmacoinvasive strategy in comparison with primary percutaneous transluminal coronary angioplasty in patients with ST-segment elevation myocardial infarction in the primary combined outcome of cardiovascular death, reinfarction, stroke, and cardiogenic shock at in-hospital follow-up. Specific objectives will include knowing the frequency of major bleeding, stroke, and all-cause mortality at 12 months of follow-up.

\section{Sample size calculation}

The primary objective will be to compare the composite outcome of cerebrovascular disease (CVD), reinfarction, cardiogenic shock, and cardiovascular death, after predicting a statistical power (1- $\beta$ ) of $80 \%$, an $\alpha$ level of 0.05 , and taking into account, a predicted rate of the primary outcome of $12.4 \%$ at follow-up day 30 in patients treated with reperfusion and a maximum tolerated degree of difference (non-inferiority - d) of $5 \%$; a total sample of 157 patients per arm are calculated for demonstrating non-inferiority of the pharmacoinvasive strategy versus primary angioplasty. If an attrition rate of $10 \%$ is assumed, a final total sample of 344 patients is calculated. Enrollment started on April 1, 2018, and its completion is expected by March 31, 2020. The review and analysis of the information are expected to be available to submit for publication to a journal of large circulation by the second semester of 2020 


\section{Statistical Analysis}

\section{Study variables}

In addition to the main variables, the following will be collected:

- ST-segment elevation myocardial infarction: patients with chest pain of angina pectoris with ST-segment elevation on 12-lead electrocardiogram. ST-segment elevation should appear on two contiguous leads, larger than $2.5 \mathrm{~mm}$ in males younger than 40 years, larger than $2 \mathrm{~mm}$ in males older than 40 years, or larger than 1.5 $\mathrm{mm}$ in females, on V2-V3 electrocardiographic leads or larger than $1 \mathrm{~mm}$ on any other lead.

- Time to first medical contact: period of time, measured in minutes, from the onset of symptoms indicative of ischemia until receiving medical care for the first time. This can be provided by a health professional or medical emergency technician.

- Site of first medical contact: place where initial medical care was provided. It may correspond to any primary, secondary, or tertiary medical center.

- Door-to-needle time: period of time, measured in minutes, from the moment of entering the site of first medical contact to the moment of receiving the fibrinolytic drug.

- Door-to-balloon time: period of time, measured in minutes, from the moment of entering the health-care site with $\mathrm{PCl}$ capacity to the advancement of the metal guidewire beyond the lesion in the infarct-related artery (IRA).

- Total ischemia time: time elapsed, measured in minutes, from the onset of symptoms indicative of ischemia to the moment of advancement of the metal guidewire beyond the lesion in the IRA. In case of receiving fibrinolysis, it will be measured from the onset of symptoms until evidence of reperfusion on ECG, after $90 \mathrm{~min}$ of fibrinolytic treatment administration.

\section{Effectiveness criteria}

Angiographic: TIMI Grade 3 anterograde flow in IRA and TMP 3 myocardial perfusion.

Electrocardiographic: ST-segment decrease of at least $50 \%$ versus initial electrocardiogram, $90 \mathrm{~min}$ after fibrinolytic agent administration.

\section{Primary outcomes}

- Combined primary outcome: cardiovascular death, cardiogenic shock, stroke, reinfarction, and cardiogenic shock at in-hospital follow-up.
- In-hospital mortality: death during index hospitalization, whether or not related to the main reason for admission.

- Stroke: loss of any cortical or subcortical region function, as a consequence of ischemia, embolism or hemorrhage, documented by computed tomography, or MRI of the skull.

- Non-lethal myocardial infarction: ST-segment elevation myocardial infarction, as previously defined, with the patient discharged alive at the end of hospital care.

\section{Secondary outcomes}

- Major hemorrhage: hemorrhage leading to death, retroperitoneal bleeding, central nervous system bleeding (including the eye), bleeding with hemodynamic repercussion, bleeding that requires surgical intervention, decompression of a closed compartment, transfusion of one or more units of packed red blood cells, hemoglobin decrease greater than $3 \mathrm{~g} / \mathrm{dL}$, or hematocrit decrease greater than $10 \%$ with regard to a previous determination.

- Minor hemorrhage: microscopic hematuria unrelated to urethral trauma, epistaxis requiring tamponade or surgical intervention, gastrointestinal tract bleeding, conjunctival bleeding, hematoma larger than $5 \mathrm{~cm}$, bleeding reducing hemoglobin less than $3 \mathrm{~g} / \mathrm{dL}$.

- TIMI flows, documented by invasive coronary angiography, and categorized as follows: TIMI 0: complete flow absence; TIMI 1: contrast medium partial penetration, without crossing the causative lesion or filling the distal coronary artery; TIMI 2: contrast medium penetration beyond the causative lesion, without filling the coronary artery or, otherwise, slower than normal coronary arteries; and TIMI 3: normal coronary arterial flow.

- Mortality at 12 months of follow-up.

\section{Discussion}

The PHASE-MX study aims to demonstrate, through a real-life observational analysis (i.e., without randomization or control of variables), that fibrinolysis and subsequent $\mathrm{PCl}$ in patients with STEMI is not inferior in efficacy versus $\mathrm{PCl}$. The strengths of this study lie on three points; the first one refers to the absence of randomization and control groups; the second, to fibrinolysis administration in a wide variety of clinical contexts, and the third, to the performance of $\mathrm{PCl}$ in a national reference center, regarded as high volume in coronary 
angioplasty. The main weaknesses of this study include the probability of patients not being transferred to the inclusion center due to the severity of their clinical condition and the wide variety of coadjuvant treatment.

One of the main implications derived from the findings of this study is to support a wider use of fibrinolysis in Mexico, where availability of hemodynamic laboratories is limited. In addition, it is likely to be the scientific support of promotional campaigns for the care of myocardial infarction in Mexico.

\section{Funding}

The authors received no sponsorship for carrying out this protocol. The authors covered all generated expenses.

\section{Conflicts of interest}

The authors declare that they have no conflicts of interest.

\section{Ethical disclosures}

Protection of people and animals. The authors declare that no experiments were performed on humans or animals for this investigation.

Confidentiality of data. The authors declare that they have followed the protocols of their work center on the publication of patient data.

Right to privacy and informed consent. The authors declare that no patient data appear in this article.
This research protocol was submitted to the Committee of Ethics and Research of Instituto Nacional de Cardiología Ignacio Chávez, with registration number PT-19-109. In addition, it was registered on the ClinicalTrials.gov platform with identifier NCT03974581.

\section{References}

1. Secretaría de Salud. La atención del infarto agudo al miocardio en México. Estudio de oferta y demanda y análisis económico ex ante de un programa nacional de reducción de la mortalidad por infarto agudo al miocardio. Ciudad de México, 2017.

2. GUSTO investigators. An international randomized trial comparing thrombolytic strategies for acute myocardial infarction. NEJM. 1993; 32(10):673-682.

3. Keeley EC, Boura JA, Grines CL. Primary angioplasty versus intravenous thrombolytic therapy for acute myocardial infarction: a quantitative review of 23 randomised trials. The Lancet. 2003;361(9351):13-20.

4. Agewall S, Camm J, Barón Esquivias G, Budts W, Carerj S, Casselman F, et al. Guía ESC 2016 sobre el diagnóstico y tratamiento de la fibrilación auricular, desarrollada en colaboración con la EACTS. Rev Esp Cardiol. 2017;70(1):50.1-50.e84

5. Andersen HR, Kelbaek H, Madsen JK, Lomholt P, Mortensen LS. A comparison of coronary angioplasty with fibrinolytic therapy in acute myocardial infarction. N Engl J Med. 2003;349 (8):733-742.

6. Bonnefoy E, Steg PG, Boutitie F, Dubien P-Y, Lapostolle F, Roncalli J, et al. Comparison of primary angioplasty and pre-hospital fibrinolysis in acute myocardial infarction (CAPTIM) trial: a 5-year follow-up. Eur Heart J. 2009;30(13):1598-606

7. Armstrong PW, Gershlick AH, Goldstein P, Wilcox R, Danays T, Lambert $\mathrm{Y}$, et al. Fibrinolysis or primary $\mathrm{PCl}$ in ST-segment elevation myocardial infarction. N Engl J Med. 2013;368(15):1379-87.

8. Steg PG, Bonnefoy E, Chabaud S. Impact of time to treatment on mortality after prehospital fibrinolysis or primary angioplasty: data from the captim randomized clinical trial. ACC Curr J Rev. 2004;13(3):56-7.

9. Pu J, Ding S, Ge H, Han Y, Guo J, Lin R, et al. Efficacy and safety of a pharmaco-invasive strategy with half-dose alteplase versus primary angioplasty in ST-segment-elevation myocardial infarction: EARLY-MYO Trial (Early Routine Catheterization After Alteplase Fibrinolysis Versus Primary PCI in Acute ST-Segment-Elevation Myocardial Infarction). Circulation. 2017;136(16):1462-73.

10. Fernández-Avilés F, Alonso JJ, Pena G, Blanco J, Alonso-Briales J, López-Mesa J, et al. Primary angioplasty vs. early routine post-fibrinolysis angioplasty for acute myocardial infarction with ST-segment elevation: the GRACIA-2 non-inferiority, randomized, controlled trial. Eur Heart J. 2007:28(8):949-60.

11. Araiza-Garaygordobil D, Arias-Mendoza A, Martínez-Sánchez C, Martínez-Ríos MA, Ajit MS. Reperfusion of myocardial infarction in India: notions for México. Arch Cardiol México. 2018;88(2):148-52.

12. Instituto Nacional de Estadística y Geografía. Censo Nacional de Población y Vivienda 2010. 1era ed. Ciudad de México, México. 2011. 